\title{
A questão indígena no Serviço Social: um debate necessário na profissão
}

The issue of indigenous peoples in Social Work: a necessary debate in the profession

\author{
Wagner Roberto do Amaral* \\ Jenifer Araújo Barroso Bilar**
}

\begin{abstract}
Resumo - Este artigo intenciona refletir sobre os desafios em torno da (in)visibilidade da questão indígena no âmbito da produção acadêmica do Serviço Social e nos documentos publicizados por entidades representativas da profissão no Brasil. Agrega reflexões sobre a importância da questão indígena associada à questão étnico-racial, temáticas emergentes e progressivamente pautadas pela categoria profissional dos assistentes sociais brasileiros enquanto componentes estruturantes da questão social no Brasil. O presente trabalho é resultado parcial de pesquisa realizada pelos autores por meio da análise de documentos produzidos por entidades representativas da categoria profissional e de artigos publicados em periódicos e anais de eventos acadêmicos na área de Serviço Social. Apesar dos avanços identificados pela recente inserção da questão indígena no âmbito da categoria profissional, constatou-se o reduzido número de publicações acerca da questão indígena, sendo premente ampliar as reflexões sobre esta temática pela área do Serviço Social.

Palavras-chave: povos indígenas; assistentes sociais indígenas; educação superior indígena; ações afirmativas.

Abstract - This article intends to reflect on the challenges surrounding the (in)visibility of the indigenous peoples in Social Work academic production and in documents published by entities representing the profession in Brazil. It aggregates reflections on the importance of the indigenous issue associated with the ethnic-racial issue. These are emerging themes, progressively more discussed by the professional
\end{abstract}

\footnotetext{
* Graduado em Serviço Social pela Universidade Estadual de Londrina; Mestre em Educação pela Universidade Estadual Paulista Júlio de Mesquita Filho; Doutor em Educação pela Universidade Federal do Paraná; Pós-Doutor em Estudos Interculturais pela Universidad Veracruzana, México; Pós-Doutor em Políticas de Educação Superior para Povos Indígenas na América Latina pela Universidad Nacional Três de Febrero, Argentina; Professor do Departamento de Serviço Social e do Programa de Pós-Graduação em Serviço Social e Política Social da Universidade Estadual de Londrina; Membro participante do Núcleo de Estudos e Pesquisas em Gestão de Políticas Sociais da UEL e da Comissão Universidade para os Indios do Paraná. E-mail:wramaral2011@hotmail.com. ORCID: https://orcid.org/00000002-8555-5915.

** Graduada em Serviço Social pela Universidade Estadual de Londrina. Especialista em Comunicação Popular e Comunitária; Mestranda pelo Programa de Pós-Graduação em Serviço Social e Política Social da Universidade Estadual de Londrina. E-mail: jhe_araujo@hotmail.com. ORCID: https://orcid.org/0000-0002-9970-2197.
} 
category of Brazilian social workers, as structured components of the social issue in Brazil. This work is partially a result of a research conducted by the authors through the analysis of documents published by organizations representing the professional category and articles published in journals and annals of academic events in the area of social work. Although we acknowledge the advances made by the recent insertion of the indigenous issue within the scope of the professional category, we still note the small number of publications on this theme, showing that it is urgent to expand such reflections in the field of social work.

Keywords: indigenous peoples; indigenous social workers; indigenous higher education; affirmative actions.

O Serviço Social brasileiro apresenta uma trajetória histórica marcada, principalmente nos últimos 40 anos, por avanços na construção de um projeto ético-político profissional pautado na defesa das classes historicamente subalternizadas, bem como no empenho pela eliminação de todas as formas de opressão, exploração e preconceito (CFESS, 2016). Tal projeto profissional tornou-se constitutivo em dimensões teórico-metodológicas, ético-políticas e técnico-operativas fundamentais para a compreensão das expressões da "questão social" (NETTO, 2011) e para o seu enfrentamento no cotidiano do trabalho dos assistentes sociais.

É nesse recente percurso que passam a ser pautadas temáticas que se agregam à compreensão crítica e ampliam-na, portanto, aproximando-se da totalidade da realidade brasileira e latino-americana. Um elenco de novas leituras e reflexões passou a compor o arsenal teórico-investigativo e formativo das e dos assistentes sociais, dos quais destacam-se neste texto e neste contexto a questão étnico-racial e, associada a esse debate, a questão indígena. O que denominamos nesse texto como questão indígena se revela intimamente articulado e dimensionado à questão étnico-racial, tendo em vista estarem conectados a ofensivas colonialistas e capitalistas semelhantes, ainda que, para os povos indígenas, a questão territorial seja vital e tenha profunda centralidade nesse processo.

A expressão "étnico" da questão étnico-racial revela as atrocidades, etnocídios e desumanidades cometidas pelo modo de produção capitalista em seu processo de expansão e consolidação, impactando povos indígenas inteiros e, portanto, originários desse território, assim como as populações africanas afetadas pela diáspora e pela escravidão colonialista.

A questão racial - evidenciada pela diáspora africana, pela escravidão de milhões de mulheres e homens exportados como mercadoria e pela exploração da força de trabalho de trabalhadoras/es negras/os -, segundo Gonçalves (2018, p. 515), "sustentou a conformação do antagonismo entre as classes sociais, isto é, foi alicerce da desigual distribuição de riquezas no emergente capitalismo brasileiro". Assim como a primeira, a questão indígena também encontra-se profundamente vinculada à questão social. Esta vinculação mostra-se através das ofensivas capitalistas de usurpação 


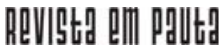

\} A QUESTÃO INDÍGENA - AMARAL, W. R.; BILAR, J. A. B. \}

DOI: $10.12957 /$ REP.2020.52013

de territórios tradicionais, dos etnocídios e dos processos de negação e ocultamento oficial de pertencimentos étnicos no intento da constituição dos indígenas como "trabalhadores nacionais" (PACHECO DE OLIVEIRA; FREIRE, 2006; LUCIANO, 2006).

Desta forma, a questão indígena, componente explícita da questão étnico-racial, além de, per si, denunciar os processos etnocidas marcados pelas violências, epidemias, escravidão, mortes, torturas, omissões, invisibilidades, preconceitos e expropriação territorial vivenciados pelos povos indígenas há mais de 520 anos de contato (historicamente conectado aos processos de escravidão negra no país), revela ainda as diferentes estratégias de luta e de resistência destas populações (PACHECO DE OLIVEIRA; FREIRE, 2006; LUCIANO, 2006). Tais memórias, lutas e resistências históricas se manifestam pela presença e intensa atuação dos movimentos e organizações indígenas no Brasil e na América Latina, tendo avançado, sobremaneira, desde a década de 1970, alcançando conquistas constitucionais importantes, ainda que muitas delas ainda não efetivadas.

Tais resistências históricas se evidenciam, ainda e teimosamente, no campo da produção do conhecimento em distintas áreas e em diferentes categorias profissionais, sendo o Serviço Social um espaço potencial e profícuo nessa temática, haja vista sua configuração ético-política. Essa produção científica e acadêmica tem se apresentado num contexto recente não somente pela autoria de pesquisadores não indígenas, mas, fundamentalmente, por intelectuais e pesquisadores indígenas de distintos pertencimentos étnicos.

Almeida (2017) reflete sobre a importância da inclusão das temáticas de gênero e da questão étnico-racial na esteira das discussões nacionais sobre o código de ética dos assistentes sociais, bem como sobre a proposta nacional de currículo mínimo para o curso de Serviço Social. Dessa forma, Almeida (2017, p. 36) as considera um avanço na democratização da profissão, fundamentalmente pela inclusão da realidade do racismo, possibilitando "o fortalecimento do Serviço Social e de sua direção política pela construção de uma nova ordem societária, em defesa da classe trabalhadora". Argumentando sobre o perverso saldo do colonialismo europeu para o povo negro no Brasil e sua íntima e estruturante associação com o modo de produção capitalista, a autora afirma que:

É a história da luta de classes e, nesse contexto, a hegemonia dos padrões civilizatórios euro norte-americanos tem provocado silenciamentos, invisibilidades e dores para aqueles (as) que não escolhem ou vivenciam a supremacia branca como expressão de sua existência. (ALMEIDA, 2017, p. 36).

É nessa perspectiva que a inclusão da temática indígena no Serviço Social brasileiro se apresenta - profunda e historicamente associada aos processos originais de exploração, espoliação e etnocídio colonial presentes 


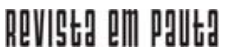

\} A QUESTÃO INDÍGENA - AMARAL, W. R.; BILAR, J. A. B. \}

DOI: $10.12957 /$ REP.2020.52013

desde os primeiros contatos entre os povos originários habitantes desse território com os arautos da expansão constitutiva do modo de produção capitalista, do século XVI até a contemporaneidade. Contudo, revela ainda as profundas e históricas expressões de resistência, lutas e organização dos povos indígenas no Brasil e em toda América Latina (MILHOMENS; BARROSO, 2019).

Dessa forma, esse artigo pretende contribuir com o processo de aproximação e diálogo entre a questão indígena e o Serviço Social, agregando-se à teimosia histórica de luta contra o racismo e de afirmação dos direitos dos povos originários do nosso país e do nosso continente.

\section{A questão indígena constitutiva à questão social brasileira}

A questão indígena brasileira se apresenta e está marcada desde o início do século XVI pela relação impositiva e violenta entre o projeto colonialista europeu e os povos originários habitantes desse território, orientados, fundamentalmente, pelos interesses mercadológicos de expansão capitalista de exploração dos recursos naturais existentes e expropriação dessas terras. Segundo Pacheco de Oliveira e Freire (2006), diferentes registros e estudos indicam que o Brasil do ano de 1500 era habitado por cerca de 1.400 povos indígenas diferentes, com estimativas que vão de 1.500 .000 a 5 milhões de pessoas. Inúmeras pesquisas arqueológicas assinalam ainda a ocupação do território brasileiro por populações paleoíndias há mais de 12 mil anos (FUNARI; NOELLI, 2005).

Os diferentes contextos históricos - Período Colonial, Imperial e as diferentes fases republicanas - redesenharam a relação entre Estado e sociedades indígenas, sempre mediadas pela expropriação, usurpação e exploração dos seus territórios tradicionais, seja pelas monoculturas agrícolas e agropecuários, seja pelos empreendimentos públicos e privados telegráficos, ferroviários, hidroelétricos e de transmissão elétrica, rodoviários, de mineradoras etc., bases fundamentais para a estruturação urbano-industrial no país. Destaca-se ainda, no Período Colonial, a existência da escravidão indígena, que caracterizou a caça e o aprisionamento de milhares de pessoas indígenas e seu envio para o trabalho escravo em fazendas (GORENDER, 2016).

Os intentos colonialistas nos períodos Colonial, Imperial e Republicano apostaram intensamente na descaracterização eugênica das populações indígenas enquanto estratégia de amansamento, miscigenação e conversão como trabalhadores nacionais, e de forma homogênea na construção simbólica da noção de "povo brasileiro" (RIBEIRO, 1995), também associado ao ideário da democracia racial. Constitui-se, desta forma, a genérica, simbólica e perversa expressão do "índio brasileiro", representado pelas manifestações artísticas europeias e pela nascente literatura brasileira. 


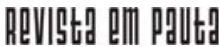

\} A QUESTÃO INDÍGENA - AMARAL, W. R.; BILAR, J. A. B. \}

DOI: $10.12957 /$ REP.2020.52013

Tal empreitada passa a ser subvertida por processos de resistência dos povos indígenas ao comporem fronteiras étnicas (BARTH, 1998), reconstituírem suas identidades e seus critérios próprios de indianidade nos contextos e situações específicas de contato (CUNHA, 1987).

Os povos indígenas no Brasil, comum e vulgarmente chamados de "índios", são historicamente marcados por estereótipos, percebidos ora como "um ser sem civilização, sem cultura, incapaz, selvagem, preguiçoso, traiçoeiro, etc.", ora como "um ser romântico, protetor das florestas, símbolo da pureza, quase um ser como o das lendas e dos romances" (LUCIANO, 2006, p. 30). O desconhecimento sobre essas populações, seus distintos modos de ser, suas tradições, sua diversidade étnica e linguística, suas resistências históricas e seus pertencimentos territoriais pode ter como consequência a reprodução de visões preconceituosas e de atitudes discriminatórias no cotidiano da vida social e, fundamentalmente, do exercício profissional.

Os resultados do Censo IBGE, realizado no ano de 2010, evidenciaram a existência de 305 grupos étnicos diferentes, falantes de 274 línguas indígenas distintas no Brasil (concentrando uma das maiores diversidades étnicas indígenas do planeta), totalizando mais de 896,9 mil indígenas - o que representava, aproximadamente, $0,47 \%$ da população do país, sendo que, destes, 36\% vivem em espaços urbanos (IBGE, 2010). Gersem dos Santos Luciano (2006), pesquisador pertencente ao povo Baniwa, aponta que não existe nenhum povo, tribo ou clã com a denominação de "índio". Segundo o referido autor, cada "índio" pertence a um povo, a uma etnia identificada por uma denominação própria, ou seja, a autodenominação como Guarani, Yanomami, Kaingang, Bororo, Pankararu etc.

Ao abordar os modos de vida dos povos indígenas, Luciano (2006, p. 101) destaca que "o território indígena é sempre a referência à ancestralidade e a toda a formação cósmica do universo e da humanidade é nele que se encontram presentes e atuantes os heróis indígenas, vivos ou mortos". Assim, as constantes invasões dos territórios indígenas aprofundam ainda mais sua vulnerabilidade identitária, cultural e social. Segundo Yazbek (2012), partindo dos dados do Plano Brasil Sem Miséria, da totalidade da população indígena no país, 326.375 se encontram na extrema pobreza, representando cerca de $40 \%$ desse contingente populacional. Como reflexo deste contexto, somam-se problemas como alcoolismo, depressão, suicídios, violência e discriminação, entre outros. Os povos indígenas na atualidade estão submetidos a precárias condições de vida, tendo como principal causa a não demarcação de seus territórios e a omissão do Estado brasileiro em garantir infraestrutura e políticas sociais necessárias diante da ofensiva do agronegócio.

Outrossim, a Constituição Federal de 1988 preconiza, em seus artigos 231 e 232, o direito às especificidades culturais indígenas, decorrentes das suas formas de organização social, costumes, línguas, crenças e tradições, 


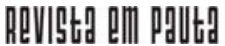

\} A QUESTÃO INDÍGENA - AMARAL, W. R.; BILAR, J. A. B. \}

DOI: $10.12957 /$ REP.2020.52013

bem como o direito originário sobre as terras que tradicionalmente ocupam. Reconhece ainda os indígenas como cidadãos de direitos, considerados em suas realidades culturais diferenciadas. Tais direitos vêm se constituindo em bandeira das lutas de diversas organizações e movimentos indígenas no Brasil, pautando para as diferentes instâncias governamentais a efetivação de políticas públicas e sociais voltadas às especificidades étnicas e territoriais dessas populações. Amaral, Bilar e Rodrigues (2014) destacam os avanços legais em políticas sociais específicas, como as da saúde e da educação; contudo, ainda estão distantes das necessidades pautadas pelos povos indígenas.

Sendo a questão social um eixo fundamental orientador da formação profissional dos assistentes sociais, está presente no documento das diretrizes curriculares para o curso de Serviço Social. Segundo Netto (2011), na era do capitalismo monopolista constata-se o acirramento da questão social em decorrência da precarização das condições de trabalho e de vida da classe trabalhadora. Neste contexto de monopolização do capital, o Estado passa a intervir de forma sistemática através de políticas públicas, possibilitando a emersão e constituição do Serviço Social e da categoria dos assistentes sociais para atuarem nas políticas sociais, sendo este, desde então, um espaço ocupacional por excelência para estes trabalhadores.

Ademais, convivemos com a intensa ofensiva do neoliberalismo, que, por sua vez, visa ao desmonte cada vez maior dos direitos sociais. Os direitos sociais estão, portanto, em uma arena de constante disputa, enfrentando dilemas para sua efetivação enquanto conquista social. Todavia, no que tange ao reconhecimento da questão indígena enquanto expressão da questão social, assim como das lutas e enfrentamentos dos povos indígenas por políticas, planos, programas, projetos, serviços e benefícios públicos específicos, torna-se premente a necessidade de pautar essa temática no interior da profissão de Serviço Social.

\section{Balizadores para a compreensão da questão indígena no Serviço Social}

O projeto ético-político do Serviço Social tem como aportes fundamentais o código de ética profissional (Resolução CFESS no 273, de 1993), a lei que regulamenta a profissão de assistente social (Lei no 8.662 , de 1993) e as Diretrizes curriculares para o curso de Serviço Social (ABEPSS, 1996). O código de ética profissional de 1993 apresenta um total de 11 princípios fundamentais; os princípios $\mathrm{VI}, \mathrm{VIII}$ e XI se referem diretamente aos aspectos associados à dimensão étnica e ao respeito à diversidade. Neste sentido, a profissão afirma o seu compromisso de defesa das classes historicamente subalternizadas, bem como o empenho na eliminação de todas as formas de preconceito e discriminação. 


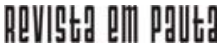

\} A QUESTÃO INDÍGENA - AMARAL, W. R.; BILAR, J. A. B. \}

DOI: $10.12957 /$ REP.2020.52013

A Lei no 8.662 , de 7 de junho de 1993, que regulamenta a profissão de assistente social no Brasil, destaca em seu artigo $4^{\circ}$, parágrafo $\mathrm{V}$ e IX, que constitui como competência do assistente social: "V - Orientar indivíduos e grupos de diferentes segmentos sociais no sentido de identificar recursos e de fazer uso dos mesmos no atendimento e na defesa de seus direitos;" e "IX - Prestar assessoria e apoio aos movimentos sociais em matéria relacionada às políticas sociais, no exercício e na defesa dos direitos civis, políticos e sociais da coletividade" (BRASIL, 1993, p.1)

O documento Diretrizes gerais para o curso de Serviço Social vigente foi elaborado e publicado no ano de 1996 pela então Associação Brasileira de Escolas de Serviço Social (ABESS), posteriormente atualizado e publicado como Diretrizes curriculares para os cursos de Serviço Social pelo Conselho Nacional de Educação, por meio da Resolução CNE $n^{\circ}$ 15/ 2002. Preconiza que a formação profissional tenha como base a apreensão das dimensões teórico-metodológica, ético-política e técnico-operativa.

No que tange à questão étnico-racial, nela contida a questão indígena, e ao currículo para os cursos de Serviço Social, entendemos que o debate étnico-racial se constitui como um elemento estruturante das relações sociais, sendo imprescindível que as propostas curriculares das unidades de ensino de Serviço Social incorporem conteúdos afeitos a esta temática de maneira transversal, buscando superar a secundarização e a invisibilidade deste debate na formação e na atuação profissional. As entidades organizativas da categoria, tais como o Conselho Federal de Serviço Social (CFESS), os Conselhos Regionais de Serviço Social (CRESS), a Executiva Nacional de Estudantes de Serviço Social (ENESSO) e a Associação Brasileira de Ensino e Pesquisa em Serviço Social (ABEPSS) têm promovido iniciativas com o objetivo de orientar e provocar a reflexão dos assistentes sociais diante das variadas formas de preconceito com as quais estes se deparam no cotidiano profissional.

Nos anos de 2012 e 2013, foram lançados dois boletins pelo CFESS Manifesta sobre a temática indígena na gestão "Tempo de Luta e Resistência" (2011-2014). Estes refletem o posicionamento da categoria profissional partindo dos compromissos firmados no $40^{\circ}$ Encontro Nacional CFESS/CRESS, e reafirmados no $41^{\circ}$ Encontro Nacional CFESS/CRESS, que ocorreram, respectivamente, nos anos de 2011 e 2012. O Conjunto CFESSCRESS, no $40^{\circ}$ Encontro Nacional, afirma seu compromisso com a questão indígena, defendendo os seguintes pontos:

- intensificação da discussão, no Conjunto CFESS-CRESS, sobre a questão indígena no Brasil, a população quilombola e comunidades tradicionais, o aparato legal (legislação) que as regem, o estudo sobre o acesso desses segmentos às políticas públicas, apoiando a luta pela demarcação das terras.

- articulação e apoio às lutas dos movimentos sociais pelo direito à terra, pela moradia digna, pelos direitos dos povos originários, 


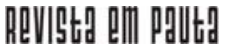

\} A QUESTÃO INDÍGENA - AMARAL, W. R.; BILAR, J. A. B. \}

DOI: $10.12957 /$ REP.2020.52013

quilombolas, população em situação de rua e catadores/as de materiais recicláveis. (CFESS, 2012b, p. 2).

Cabe ainda destacar que, no ano de 2010, foi criado um grupo temático de pesquisa (GTP), no âmbito da ABEPSS, denominado Serviço Social, relações de exploração/opressão de gênero, raça/etnia e sexualidades, voltado à reflexão acadêmica e política acerca de tais temas. $\mathrm{O}$ documento Subsídios para o debate sobre a questão étnico-racial na formação em Serviço Social é de iniciativa do referido GTP durante a gestão da ABEPSS nos anos de 2017-2018. O objetivo era subsidiar a inclusão e o fortalecimento do debate da questão étnico-racial, buscando contribuir para uma formação em Serviço Social antirracista a partir do desenvolvimento de atividades de ensino, pesquisa e extensão (graduação e pósgraduação) (ABEPSS, 2018). Entretanto, segundo o documento:

Ainda temos uma tímida produção e ações políticas - embora estejam numa crescente - no campo da luta antirracista no Serviço Social, que reverbera na formação profissional limitando o aprofundamento de uma análise da totalidade da realidade brasileira, ou seja, em que medida o racismo impacta o processo de formação e trabalho profissional. (ABEPSS, 2018, p. 11).

Cabe destacar que o referido documento centra sua atenção no debate racial, realizando uma breve reflexão sobre os aspectos étnicos, embora o próprio texto reconheça a distinção entre estas duas categorias. Destacamos também que o CFESS - triênio 2014/2017 - lançou a série de cadernos intitulados Assistente social no combate ao preconceito, abordando os temas: "O que é o preconceito?" (Caderno 1); "O estigma do uso de drogas" (Caderno 2); "Racismo" (Caderno 3); "Transfobia" (Caderno 4); e "Xenofobia" (Caderno 5).

$\mathrm{Na}$ abordagem ao racismo, o Caderno 3 apresenta uma síntese a respeito do tema, visando contribuir para a qualificação profissional do assistente social neste debate. Tal caderno destaca a diferença entre raça e etnia, se detendo à questão racial; a questão indígena é timidamente citada em dois momentos do texto; num primeiro momento, ao destacar a situação de desigualdade na qual os povos indígenas estão envolvidos: "[...] em todas as esferas da vida social, as populações negra e indígena são as que mais aparecem em desvantagens socioeconômicas e de representação em espaços de poder e decisão" (CFESS, 2016, p. 7). Num segundo momento, o texto cita os indígenas apenas ao abordar o perfil étnico-racial da população, apontando a importância do uso das categorias já empregadas pelo IBGE nos formulários e documentos de registro de informação dos serviços públicos e de atendimento à população, para fins de formulação de políticas sociais. 


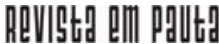

\} A QUESTÃO INDÍGENA - AMARAL, W. R.; BILAR, J. A. B. \}

DOI: $10.12957 / R E P .2020 .52013$

Atualmente há, no estado do Paraná, sete assistentes sociais indígenas; destes, apenas dois são do sexo masculino. A presença destes sujeitos andarilhando pelos espaços acadêmicos e pelas suas comunidades de pertencimento instiga muitas reflexões e possibilidades no que se refere ao seu duplo pertencimento (AMARAL, 2010). Contudo, ao abordarmos o CFESS e o CRESS-PR solicitando a disponibilização de informações referentes ao quantitativo de assistentes sociais indígenas cadastrados nestes órgãos ${ }^{1}$, tivemos como devolutiva o parecer de que estes não possuem conhecimento de assistentes sociais indígenas registrados em tais órgãos e que os modelos de requerimento "padrão do conjunto CFESS/CRESS" não preveem campo para identificação do quesito "raça". Neste sentido, ainda é notório o desconhecimento, o não reconhecimento e a ausência de registros e sistematização acerca da existência e da quantidade de profissionais indígenas que atuam nos níveis estadual e nacional.

Em nossa análise, os documentos citados centram suas reflexões na questão racial e nos desdobramentos dos preconceitos vivenciados pela população negra no Brasil. Ainda que ancore esse debate na questão étnicoracial, muito pouco se refere à questão indígena. Talvez isso se apresente tendo em vista o progressivo aumento de profissionais, pesquisadoras e pesquisadores negros no interior da profissão, pautando esta temática nos eventos acadêmicos e da categoria profissional.

\section{A questão indígena na produção acadêmica do Serviço Social}

Com a intenção de levantar e identificar a temática indígena na produção acadêmica do Serviço Social brasileiro, realizamos a busca por artigos publicados em dois periódicos, bem como por trabalhos apresentados e registrados nos anais de um evento de âmbito internacional dessa área. No universo dos periódicos vinculados à área de Serviço Social, foram selecionadas as versões on-line da Revista Serviço Social e Sociedade e da Revista Katálysis, sendo essa escolha justificada por possuírem significativa relevância e circulação na área de Serviço Social, em âmbito nacional e internacional, além de serem avaliadas como Qualis A-1 pela Coordenação de Aperfeiçoamento de Pessoal de Nível Superior (CAPES). Buscamos identificar, nestas revistas, publicações que abordassem a questão étnico-racial, com ênfase na temática indígena, tendo como recorte temporal o período de 2015 a 2019.

Ao analisar a Revista Serviço Social e Sociedade, identificamos que, no ano de 2015, foram publicados 33 artigos, sendo que apenas uma publicação aborda a questão étnico-racial com foco para a desigualdade

\footnotetext{
${ }^{1}$ Destacamos o envio de ofício ao CFESS e ao CRESS-PR no mês de novembro de 2018, solicitando as referidas informações. A escolha do CRESS-PR se justifica pela área de delimitação da pesquisa sobre as/os indígenas assistentes sociais no Paraná, desenvolvida no âmbito da investigação realizada pelos autores do trabalho.
} 


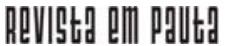

\} A QUESTÃO INDÍGENA - AMARAL, W. R.; BILAR, J. A. B. \}

DOI: $10.12957 /$ REP.2020.52013

racial no ambiente escolar. Nas edições dos anos de 2016 e 2017, nenhum dos 53 artigos publicados abordavam aspectos da questão étnico-racial.

Outrossim, no ano de 2018, do total de 27 artigos publicados, nove abordaram a questão étnico-racial, sendo que, destes, dois tratavam da questão indígena. Destaca-se o artigo de Elizângela Cardoso de Araújo Silva intitulado Povos indígenas e o direito à terra na realidade brasileira, cuja autora é pesquisadora e assistente social indígena pertencente à etnia Pankararu. Por sua vez, Joaquina Barata publicou o artigo intitulado Etnias amazônicas: confrontos culturais e intercorrências no campo jurídico.

No ano de 2019, foram publicados 27 artigos pela Revista Serviço Social e Sociedade, nenhum dos quais faz menção aos povos indígenas. Por sua vez, ao analisarmos a Revista Katálysis, identificamos que nos anos de 2015, 2016 e 2017 esse periódico publicou 89 artigos, sendo que nenhum deles abordava a temática indígena e apenas um se refere à questão racial. Em 2017 foi publicado o artigo das autoras Juceli Aparecida Silva e Eliane Lima da Silva intitulado Contribuições gramscianas sobre raça, identidade cultural e velhice na perspectiva de Stuart Hall. O artigo aborda a temática racial e a identidade cultural, todavia, não faz menção à questão indígena.

Já no ano de 2018, foram publicados 49 artigos por essa revista, sendo que, destes, apenas quatro abordavam a questão étnico-racial, mas apenas um focado na temática indígena. A autoria é de Felipe Andrés Saravia e Juan Saavedra, e o texto se intitula Desigualdades geracionais, de gênero e étnicas entre os assistentes sociais chilenos, elaborado em língua espanhola.

No ano de 2019, foram publicados 49 artigos pela Revista Katálysis, sendo que apenas dois se referiam à questão racial e nenhum abordou especificamente a temática indígena. O primeiro deles, de autoria de Nailsa Maria Souza Araujo, Érica da Silva Mendonça, Jane Mara de Araujo Costa e Jociane Pinheiro da Silva, é intitulado Conflitos socioambientais no Nordeste brasileiro: tema de interesse para o Serviço Social; por outra parte, o segundo, de Sandra Maria Batista Silveira e Maria das Graças e Silva, é intitulado Conflitos socioambientais por água no Nordeste brasileiro: expropriações contemporâneas e lutas sociais no campo.

Portanto, apesar da relevância dos dois periódicos estudados para o Serviço Social brasileiro, constata-se que pouco se tem avançado na disseminação da produção acadêmica acerca da questão étnico-racial, em especial sobre a temática indígena.

No que se refere ao levantamento de trabalhos com recorte étnico-racial e especificamente indígena em eventos acadêmicos e científicos para o Serviço Social brasileiro, foram identificados eventos nacionais e internacionais de significativa relevância e contribuições para a área, destacando-se: o Encontro Nacional de Pesquisadoras/es em Serviço Social (ENPESS), que está em sua $17^{\text {a }}$ edição; a Jornada Internacional de Políticas Públicas (JOINP), em sua 9a edição; o Congresso Brasileiro de Assistentes 


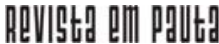

\} A QUESTÃO INDÍGENA - AMARAL, W. R.; BILAR, J. A. B. \}

DOI: $10.12957 / R E P .2020 .52013$

Sociais, na $16^{a}$ edição; o Encontro Internacional de Política Social, em sua $7^{\text {a }}$ edição; o Encontro Nacional de Política Social (ENPS), que está em sua $14^{a}$ edição²; e o Congresso Internacional de Política Social e Serviço Social, que se encontra em sua $3^{\text {a }}$ edição ${ }^{3}$.

Tendo em vista a revisão bibliográfica proposta nesse artigo, apresentamos a análise dos anais do Congresso Internacional de Política Social e Serviço Social. As referências dos registros dos demais eventos citados encontram-se em análise para posterior publicização.

A primeira edição do Congresso Internacional de Política Social e Serviço Social ocorreu em junho de 2015, na qual foram apresentados três trabalhos que abordam a temática indígena. O primeiro se refere ao artigo intitulado Eu, Luciane, da etnia Kaingang: o testemunho de uma assistente social indígena e seu duplo pertencimento, que investiga a experiência profissional de uma assistente social indígena. Ela, Luciane Aparecida de Paula, é assistente social pertencente ao povo Kaingang - uma das autoras do texto apresentado no evento, juntamente com outros dois pesquisadores, Amaral, Cassandre e Paula. O segundo artigo é de autoria de Jenifer Araujo Barroso Bilar, intitulado A política de assistência social e povos indígenas: uma reflexão necessária. Por fim, o terceiro artigo é de autoria de Cleverson Gonçalves, Mateus Galvão Cavatorta e Nilson Cesar Fraga, intitulado Massacre dos Kaingang em Pitangueiras- $P R$, um conflito atrelado a ideologia do branqueamento e a expansão do capital sobre os territórios indígenas.

A segunda edição do Congresso Internacional de Política Social e Serviço Social ocorreu no ano de 2017, no qual foram apresentados e publicados três trabalhos que abordam a temática indígena. O primeiro, de autoria de Wagner Roberto do Amaral, Jenifer Araújo Barroso Bilar e Rosa Domingos, intitulado Educação superior indígena: reflexões sobre percursos dos acadêmicos indígenas na Universidade Estadual de Londrina; o segundo artigo é de autoria de Cleverson Gonçalves, Mateus Galvão Cavatorta e Nilson Cesar Fraga, intitulado Território, poder e conflito: da chacina Kaingang de Pitanga-PR aos espaços de exclusão contemporâneos; por fim, foi publicado o artigo de Natália Raquel Niedermayer, Marli Renate von Borstel Roesler e Inês Terezinha Pastório, intitulado O povo Guarani e o discurso da mídia em Guaíra-PR: a forma em que a mídia retrata os conflitos de terras entre indígenas e agricultores, o trabalho.

No ano de 2019, realizou-se a terceira edição do Congresso Internacional de Política Social e Serviço Social, contando com um eixo temático específico denominado Relações étnico-raciais, povos indígenas, povos e comunidades tradicionais e políticas sociais. Nesse eixo temático foram publicados 31 artigos, sendo que dez deles abordaram especificamente a

\footnotetext{
${ }^{2} \mathrm{O}$ Encontro Internacional de Política Social e o Encontro Nacional de Política Social (ENPS) são realizados conjuntamente no município de Vitória (ES).

${ }^{3}$ O evento é uma iniciativa do Programa de Pós-Graduação em Serviço Social e Política Social da Universidade Estadual de Londrina (UEL) e integra esse congresso o Seminário Nacional de Território e Gestão de Políticas Sociais e o Congresso de Direito à Cidade e Justiça Ambiental.
} 


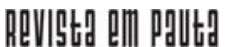

\} A QUESTÃO INDÍGENA - AMARAL, W. R.; BILAR, J. A. B. \}

DOI: $10.12957 /$ REP.2020.52013

questão indígena, dados expressivos se comparados às publicações sobre a questão indígena na área do Serviço Social. Trata-se dos seguintes artigos: Não se pode deixar de ser Guarani! As casas de reza como comunidades de práticas em meio as lutas das populações Avá-Guarani do oeste do Paraná, de autoria de Luís Fernando Moreira da Silva e Marcio Pascoal Cassandre; A temática indígena no Serviço Social: caminhos a trilhar na afirmação do compromisso ético-político da profissão, de autoria de Jenifer Araújo Barroso Bilar e Wagner Roberto do Amaral; Nhandereko Eg Kanhro: a escola indígena como espaço de fronteira, de Alexandro da Silva (estudante pertencente à etnia Guarani no curso de ciências sociais), Eliane Cordeiro (estudante pertencente à etnia Kaingang no curso de letras), Eduardo Martins Werb e Gabrielle lank; Testemunhando uma experiência empírica de pesquisa pelas lentes de uma estudante de pós-graduação indígena, de autoria de Gilza Ferreira de Souza Felipe Pereira, pesquisadora e assistente social indígena pertencente à etnia Kaingang.

Tivemos ainda, na mesma edição do evento, a publicação dos artigos Jovens Avá Guarani: estratégias de resistência no Oeste do Paraná, de autoria de Cynthia Franceska Cardoso; Um relato acerca do PROLIND no Campus da UFMS em Aquidauana - Território Etnoeducacional dos Povos do Pantanal, de autoria de Júlia Thais de Assis Moraes; A escola indígena por trás das câmeras, de autoria de Mônica Kaseker, Yago Queiroz (estudante pertencente às etnias Kaingang/Fulni-ô no curso de jornalismo) e Lucas Ribeiro; Lei 11.645/2008 no ensino fundamental: reflexos dos conflitos entre os Guarani e fazendeiros nas escolas do Oeste do Paraná, Brasil, de autoria de Eloá Soares Dutra Kastelic; e, por fim, dois artigos foram publicados, em autoria conjunta, por Elizângela Cardoso de Araújo Silva, pesquisadora e assistente social indígena pertencente à etnia Pankararu, e Codjo Olivier Sossa. Os títulos desses trabalhos são Indígenas Pankararu: os desafios da vida e trabalho fora da aldeia e Indígenas no espaço urbano: análise estatística das condições sociais da vida de indígenas no Nordeste.

Ainda que não estivesse no universo da revisão bibliográfica realizada, destacamos o reduzido número de livros publicados com a temática indígena na área do Serviço Social no Brasil. Entretanto, cumpre mencionar a obra No olho do furacão: populações indígenas, lutas sociais e Serviço Social em tempos de barbárie, organizada por William Berger (2019) e estruturada em duas partes. A primeira, constituída por sete capítulos e voltada especificamente à temática indígena (denominada como Lutas sociais, políticas sociais e povos indígenas no Brasil e na América Latina); já a segunda parte apresenta temáticas como gênero, raça/etnia, geração, formação, trabalho profissional, universidade e educação popular. Dos sete capítulos que compõem a primeira parte dessa obra, seis possuem autores/ as com formação em Serviço Social, denotando sua relevância na área.

Desse modo, a partir de nossa análise, nota-se que a questão indígena ainda é pouco abordada pela categoria profissional de assistentes 


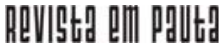

\} A QUESTÃO INDÍGENA - AMARAL, W. R.; BILAR, J. A. B. \}

DOI: $10.12957 / R E P .2020 .52013$

sociais, embora seja importante apontar o tímido avanço na apropriação destas discussões pela profissão. Destaca-se, fundamentalmente, a emergência de uma produção acadêmica voltada a essa temática, ressaltandose a inédita e emergente autoria das próprias indígenas assistentes sociais no universo analisado, com destaque para a Elizângela Cardoso de Araújo Silva pertencente à etnia Pankararu, e Luciane A. de Paula, pertencente à etnia Kaingang.

\section{Considerações finais}

A partir das pesquisas realizadas e das aproximações iniciais que viemos desenvolvendo junto à temática indígena e o Serviço Social, podemos constatar a incorporação da questão étnico-racial no interior da categoria profissional por meio dos seus órgãos de representação, fundamentalmente o Conjunto CFESS/CRESS, ENESSO e ABEPSS. Ainda que recente e progressiva, tal incorporação se apresenta fundamental para aprofundar e ampliar as compreensões acerca das expressões da questão social - seus reflexos e determinantes -, agregando a questão étnico-racial como componente estruturante na leitura da realidade, numa perspectiva de totalidade social.

Ainda que notemos avanços no posicionamento ético-político da categoria profissional em torno da questão étnico-racial, constatamos que se apresenta tímida a pauta e a visibilidade da questão indígena pelos órgãos de representação dos assistentes sociais, bem como pela produção acadêmica disseminada em eventos científicos e periódicos de significativa circulação e relevância na área. Apesar de a revisão bibliográfica realizada ter se constituído num recorte temporal e limitado a determinados periódicos e eventos acadêmicos do Serviço Social brasileiro, evidenciamos uma ênfase na questão racial, havendo ainda poucas abordagens sobre a realidade e as especificidades dos povos indígenas.

Neste sentido, apontamos a necessidade de maior reconhecimento e aprofundamento da questão indígena pelo Serviço Social, evidenciando e fortalecendo o compromisso ético-político da categoria profissional junto às classes historicamente subalternizadas, conforme prescrito nos documentos orientadores da formação e atuação dos assistentes sociais no Brasil.

Importante ainda observar a emergente presença e produção intelectual de indígenas assistentes sociais e pesquisadoras/es nos eventos acadêmicos e em periódicos. Entendemos que tão emblemática quanto a inserção e o reconhecimento da questão indígena nos documentos publicizados pelos órgãos de representação da categoria profissional dos assistentes sociais e na produção de conhecimentos em Serviço Social (seja nos eventos acadêmicos, seja nos periódicos de circulação nacional e internacional) é a recente presença e participação de estudantes e pesquisadores 


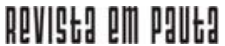

\} A QUESTÃO INDÍGENA - AMARAL, W. R.; BILAR, J. A. B. \}

DOI: 10.12957/REP.2020.52013

indígenas nos cursos de graduação e nos programas de pós-graduação, desenvolvendo pesquisas acerca de temáticas afeitas aos seus grupos étnicos e suas comunidades de pertencimento.

Os ineditismos que marcam o reconhecimento e a assunção progressiva da questão indígena pela categoria dos assistentes sociais, somados às trajetórias intelectuais das/os pesquisadoras/es indígenas na área do Serviço Social brasileiro e latino-americano ocupantes da pós-graduação e produção acadêmica, sinalizam a apropriação de novos instrumentos de luta, de resistência e de interculturalidades críticas necessárias com esses sujeitos, e não por/para eles. 


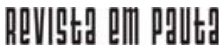

\} A QUESTÃO INDÍGENA - AMARAL, W. R.; BILAR, J. A. B. \}

DOI: $10.12957 /$ REP.2020.52013

\section{Referências}

ABEPSS. Diretrizes gerais para o curso de Serviço Social. Rio de Janeiro, 1996. Disponível em: http://www.abepss.org.br/arquivos/textos/docu mento_201603311138166377210.pdf. Acesso em: 28 fev. 2019.

ABEPSS. Subsídios para o debate sobre a questão étnico-racial na formação em Serviço Social. Vitória, 2018. Disponível em: http://www.abepss.org.br/ arquivos/anexos/subsidio_debate_uestao_etnico_servico_social-201 812041419427146430.pdf. Acesso em: 28 fev. $201 \overline{9}$.

ALMEIDA, M. da S. Diversidade humana e racismo: notas para um debate radical no Serviço Social. Argumentos, Vitória, v. 9 , n. 1, jan./abr. 2017.

AMARAL, W. R. As trajetórias dos estudantes indígenas nas universidades estaduais do Paraná: sujeitos e pertencimentos. Tese (Doutorado em Educação) - Universidade Federal do Paraná, Curitiba, 2010.

AMARAL, W. R.; BILAR, J. A. B.; RODRIGUES, M. A. Os circuitos de trabalho indígena: possibilidades e desafios para acadêmicos e profissionais Kaingang na gestão das políticas públicas. Revista Mediações, Londrina, v. 19, n. 2, 2014.

BARTH, F. Grupos étnicos e suas fronteiras. In: POUTIGNAT, P.; STREIFFFENART, J. Teorias da etnicidade. Seguido de grupos étnicos e suas fronteiras de Fredrik Barth. São Paulo: Fundação Editora da Unesp, 1998.

BERGER, W. (Org.). No olho do furacão: populações indígenas, lutas sociais e Serviço Social em tempos de barbárie. Vitória: Editora Milfontes, 2019.

BRASIL. Lei no 8.662 que regulamenta a profissão de assistente social. Brasília, 1993. Disponível em: http://www.planalto.gov.br/ccivil_03/leis/ L8662.htm. Acesso em: 25 fev. 2019.

CFESS. Código de ética do/a assistente social. Brasília, 2012a. Disponível em: http://www.cfess.org.br/arquivos/CEP_CFESS-SITE.pdf. Acesso em: 25 fev. 2019.

CFESS. CFESS manifesta. Brasília: CFESS, 2012b.

CFESS. Caderno 3. Brasília: CFESS, 2016. Disponível em: http://www.cfess. org.br/arquivos/CFESS-Caderno03-Racismo-Site.pdf. Acesso em: 25 fev. 2019.

CUNHA, M. C. Os direitos dos índios. São Paulo: Brasiliense, 1987.

FUNARI, P. P.; NOELLI, F. S. Pré-História do Brasil. São Paulo: Contexto, 2005.

GONÇALVES, R. Quando a questão racial é o nó da questão social. Katálysis, Florianópolis, v. 21, n. 3, set./dez. 2018. 


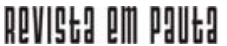

\} A QUESTÃO INDÍGENA - AMARAL, W. R.; BILAR, J. A. B. \}

DOI: $10.12957 /$ REP.2020.52013

GORENDER, J. O escravismo colonial. São Paulo: Expressão Popular, 2016. LUCIANO, G. dos S. O índio brasileiro: o que você precisa saber sobre os povos indígenas no Brasil hoje. Brasília: Ministério da Educação, 2006.

IBGE. Os indígenas no censo demográfico 2010: primeiras considerações com base no quesito cor ou raça. 2010. Disponível em: http://www.ibge. gov.br/indigenas/indigena_censo2010.pdf. Acesso em: 20 fev. 2019.

MILHOMENS, L.; BARROSO, M. Questão indígena na América Latina: lutas e resistências dos povos originários na atualidade. In: BERGER, W. (Org.). No olho do furacão: populações indígenas, lutas sociais e Serviço Social em tempos de barbárie. Vitória: Editora Milfontes, 2019.

NETTO, J. P. Capitalismo monopolista e Serviço Social. São Paulo: Cortez, 2011.

PACHECO DE OLIVEIRA, J.; FREIRE, C. A. da R. A presença indígena na formação do Brasil. Brasília: MEC/SECAD, 2006.

RIBEIRO, D. O povo brasileiro. A formação e o sentido do Brasil. São Paulo: Companhia das Letras, 1995.

YAZBEK, M. C. Pobreza no Brasil contemporâneo e formas de seu enfrentamento. Serviço Social e Sociedade, São Paulo, n. 110, abr./jun. 2012.

DOI: $10.12957 /$ rep.2020.52013

Recebido em 21 de maio de 2020.

Aprovado para publicação em 26 de maio de 2020.

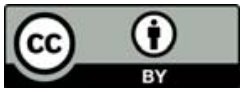

A Revista Em Pauta: Teoria Social e Realidade Contemporânea está licenciada com uma Licença Creative Commons Atribuição 4.0 Internacional. 